\title{
HICCUP AND EPHEDRINE
}

\author{
Young Zin Sohn, Lynn J. CONRad and Ronald L. Katz
}

PERsistent hiccup may occur during general anaesthesia and is sometimes troublesome, particularly when there is a need for muscle relaxation for upper abdominal, thoracic, vascular or other kinds of surgical procedures. Various authors have reported successful treatment with ketamine' ${ }^{1}$ or left phrenic nerve crush. ${ }^{2}$ Both of these treatments may be inappropriate in patients who are just recovering from anaesthesia and surgery. We wish to report the use of a single intravenous bolus of ephedrine in the treatment of hiccup.

Our attention was directed to the effect of ephedrine on hiccup several years ago when a patient developed hiccup during vascular surgery under general anaesthesia. Conventional treatments failed, but when ephedrine was given for its vasopressor effect the hiccups disappeared. This occurrence was so impressive that we decided to try this treatment on other patients using smaller doses of ephedrine.

\section{Case Report}

A 25-year-old well-developed $80 \mathrm{~kg}$ white male with a history of upper abdominal pain, dark urine, jaundice, nausea and vomiting was brought to the operating room for emergency cholecystectomy and common bile duct exploration. Past medical history was unremarkable. He had no history of allergy; was on no medication and did not smoke. His vital signs were normal as were haematocrit and serum electrolytes. Urine was positive for bile. EKG and chest $X$-ray were within normal limits.

The patient was induced smoothly and the trachea was easily intubated after pancuronium 1 $\mathrm{mg}$, thiopentone $350 \mathrm{mg}$ and succinylcholine 100 $\mathrm{mg}$. Anaesthesia was maintained with enflurane 1.5 per cent in 40 per cent oxygen and 60 per cent nitrous oxide. The patient was then given pancuronium $5 \mathrm{mg}$ and respiration was controlled

Young Zin Sohn, M.D., Assistant Professor, Lymn J. Conrad, C.R.N.A., Nurse Anaesthetist, Ronald L. Katz, M.D., Professor and Chairman. Department of Anesthesiology, UCLA School of Medicine, Los Angeles, California, 90024, U.S.A.

Address communications to: Young Zin Sohn, M.D. mechanically. A nasogastric tube was inserted after the patient was paralyzed. Vital signs were stable during this time.

About 45 minutes after skin incision and 60 minutes after induction of anaesthesia, when the common bile duct was being explored, hiccup developed. The patient was given pancuronium I $\mathrm{mg}$ and thiopentone $75 \mathrm{mg}$. The nasogastric tube was connected to a suction bottle, mechanical ventilation was changed to manual, hyperventilation was increased, anaesthesia was deepened and the nasopharynx was stimulated with the tip of a suction catheter passed through the nose. These maneuvers were carried on for about five minutes without success in abolishing the hiccup. The operation could not continue because of the vigorous hiccup and we then decided to use ephedrine. The hiccup stopped completely within 15 seconds after a single intravenous bolus administration of ephedrine $5 \mathrm{mg}$ and the operation finished without further problems. No changes in vital signs were noted after the injection of ephedrine.

An additional eleven adult patients of both sexes who developed hiccup were treated with ephedrine. In ten of the eleven patients, as in the patient reported in detail, complete relief was obtained after a single intravenous dose of $5 \mathrm{mg}$ of ephedrine. In one patient, it was completely relieved after a second dose of $5 \mathrm{mg}$ which was given about 30 seconds after the first. In nine patients ephedrine was given after other therapy had failed and in three patients it was the only treatment. An ampule of ephedrine containing 50 $\mathrm{mg}$ in $1 \mathrm{ml}$ was diluted to 1 per cent $(10 \mathrm{mg}$ per $\mathrm{ml})$ and $5 \mathrm{mg}$ was injected intravenously. We did not use ephedrine in children under 18 years of age or in hypertensive patients.

\section{Discussion}

Hiccup is a reflex intermittent clonic spasm of the diaphragm with constriction of the bronchial lumen. ${ }^{3-5}$ Hiccup may be a symptom of disease (e.g., encephalitis) or it may be seen in uraemia, alcohol intoxication or after eating or drinking. It may occur in conditions in which vagal afferent nerve endings in the abdomen are stimulated, 
particularly during intra-abdominal manipulation. If hiccup occurs because of inadequate depth of anaesthesia or inadequate relaxation, the treatment is obvious. However, hiccups sometimes appear in the presence of adequate relaxation and anaesthesia. Treatment then may be accomplished by ${ }^{1,4,5}$ deflating the stomach if it is distended, hyperventilating the patient, stimulating the mid-pharynx behind the uvula by gentle movement of a catheter inserted through the nose, intravenous injection of methylamphetamine, methylphenidate, amitryptyline, ketamine or chlorpromazine, inhalation of amylnitrate, or vagal block either by infiltration in the neck by the anaesthetist or under the diaphragm by the surgeon. These maneuvers are often unsuccessful and this probably accounts for the multiplicity of suggestions.

We wish to recommend as another mode of treatment for persistent hiccup the intravenous injection of ephedrine $5 \mathrm{mg}$ either after the traditional methods have been tried and failed, or even before some of the traditional methods have been tried. Some advantages of ephedrine over other therapy are that it may not always be advisable to deepen anaesthesia, to administer large doses of muscle relaxant, to administer ketamine or to do phrenic nerve block in a patient who is just recovering from general anaesthesia. Anaesthetists are familiar with ephedrine, which is commonly available in the operating room and we feel that this small dose of ephedrine is much safer during anaesthesia than any of the other drugs recommended. The mechanism(s) of action of ephedrine in the suppression of hiccup are not known. It might be an action as a bronchodilator, nasal decongestant, central stimulant, all of these, ${ }^{6}$ or none of them.

While the intravenous injection of ephedrine $S$ $\mathrm{mg}$ for persistent hiccup has been successful and usually stops the hiccup within 15 to 20 seconds without any significant change in blood pressure in normotensive patients, this treatment is not recommended for patients in whom ephedrine might be contraindicated.

\section{SUMMARY}

Twelve patients who developed hiccup during anaesthesia and surgery were treated successfully with an intravenous injection of ephedrine 5 mg (eleven cases) or $10 \mathrm{mg}$ (one case). In nine patients ephedrine was successful after traditional methods had been tried and failed, and in three patients ephedrine was the only agent given.

We conclude that ephedrine is a safe and easy mode of treatment for intractable hiccup during anaesthesia and surgery.

\section{RÉSUMÈ}

Douze malades atteints d'un hoquet pendant l'anesthésie et la chirurgie ont été traités avec succès par une injection intra-veineuse d'èphédrine $5 \mathrm{mg}$ (dans onze cas) ou de $10 \mathrm{mg}$ (dans un cas). Pour neuf malades, l'éphédrine a réussi là où les méthodes usuelles avaient échoué et, pour trois malades, l'éphédrine a été le seul médicament utilisé.

Nous concluons que l'éphédrine est un moyen sûr et facile de traiter le hoquet rebelle pendant l'anesthésie et la chirurgie.

\section{REFERENCES}

1. Teodorawicz, J. \& Simny, M. The effect of ketamine in patients with refractory hiccup in the post-operative period. Anaesth. Resuscit. Intens. Ther 3: 271 (1975).

2. Williamson, B.W.A. \& Macintyre, I.M.C Management of intractable hiccup. British Medical Journal 2: 501 (1977).

3. Beeson, P.B. \& MCDermotr, W. Textbook of medicine, 13th Ed., p. 876: W.B. Saunder Company (1971).

4. WYLIE, W.D. \& ChurChILl-Davioson, H.C. A practice of anaesthesia, 3rd Ed., p. 65: Lloyd-Luke (Medical Books) Ltd. (1972).

5. LEE, J.A. A synopsis of anaesthe sia, 7 th Ed., p. 782: The Williams and Wilkins Company (1973).

6. Goodman, L.S. \& GILMAN, A. The pharmacological basis of therapeutics, 5 th Ed., p. 482, p. 500: Macmillan Publishing Co., Inc. (1975). 